Eos, Vol. 90, No. 7, 17 February 2009

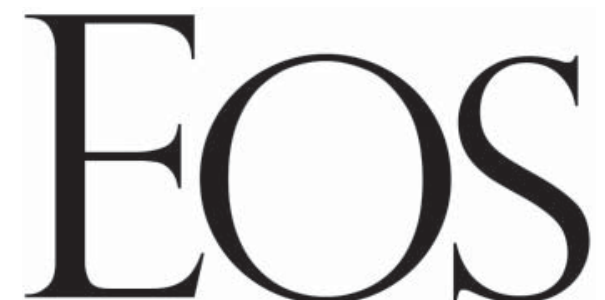

EOS, TRANSACTIONS, AMERICAN GEOPHYSICAL UNION
VOLUME 90 NUMBER 7

17 FEBRUARY 2009

\section{Ocean-Atmosphere Interactions During Cyclone Nargis}

Cyclone Nargis (Figure 1a) made landfall in Myanmar (formerly Burma) on 2 May 2008 with sustained winds of approximately 210 kilometers per hour, equivalent to a category 3-4 hurricane. In addition, Nargis brought approximately 600 millimeters of rain and a storm surge of 3-4 meters to the low-lying and densely populated Irrawaddy River delta. In its wake, the storm left an estimated 130,000 dead or missing and more than $\$ 10$ billion in economic losses. It was the worst natural disaster to strike the Indian Ocean region since the 26 December 2004 tsunami and the worst recorded natural disaster ever to affect Myanmar.

The Nargis disaster was arguably caused more by a failure to heed and act on early warnings than by a failure to observe the storm's advance [Webster, 2008]. Nonetheless, understanding the oceanic and atmospheric processes that govern the genesis, intensification, and path of severe tropical improved forecast systems for the protection of lives and property.

Nargis (Urdu for "daffodil") was spawned at a time when the international community was implementing a sustained Indian Ocean Observing System (IndOOS) for the study of phenomena spanning timescales that range from synoptic weather events to climate change [Meyers and Boscolo, 2006]. IndOOS (see Figure S1, in the electronic supplement to this Eos issue (http://www.agu.org/eos _elec/)) consists of a constellation of Earthobserving satellites for key environmental parameters such as winds, sea surface temperature (SST), and sea level plus complementary in situ networks including the Argo global float array and the Research Moored Array for African-Asian-Australian Monsoon Analysis and Prediction (RAMA, [McPhaden et al., 2009]). This article describes the evolution of Nargis and its effects on the ocean

By M. J. McPhaden, G. R. Foltz, T. LeE, V. S. N. Murty, M. RavichandRan, G. A. Vecchi, J. VIALARD, J. D. WigGERT, AND L. YU

\section{PAGES 53-54} storms can contribute to the development of as captured by elements of this observing system.

\section{Development of Nargis}

Tropical storms in the Bay of Bengal occur most frequently in October-December with a secondary peak in April-May. Relatively high $\left(28^{\circ}-30^{\circ} \mathrm{C}\right) \mathrm{SSTs}$, a thermodynamically unstable atmosphere, and low tropospheric wind shears favor these seasons for tropical storm development. Thus, the timing of Nargis was not unusual. Nor was its strength unprecedented: Cyclones of similar intensity hit Myanmar in May 1982 and April 2006. In both instances, landfall was north of the most densely populated parts of the country.

In mid-April 2008, SSTs in the Bay of Bengal were $29^{\circ}-30^{\circ} \mathrm{C}$ (Figures 2 and 3 ) and tropospheric wind shears were $30 \%$ weaker than normal. Against this backdrop, Nargis originated as a tropical depression in the southeastern Bay of Bengal on 24 April and then began tracking northwestward toward India. The depression became nearly stationary on encountering a region of climatologically high tropical cyclone heat potential (Figure 1c), where it intensified to

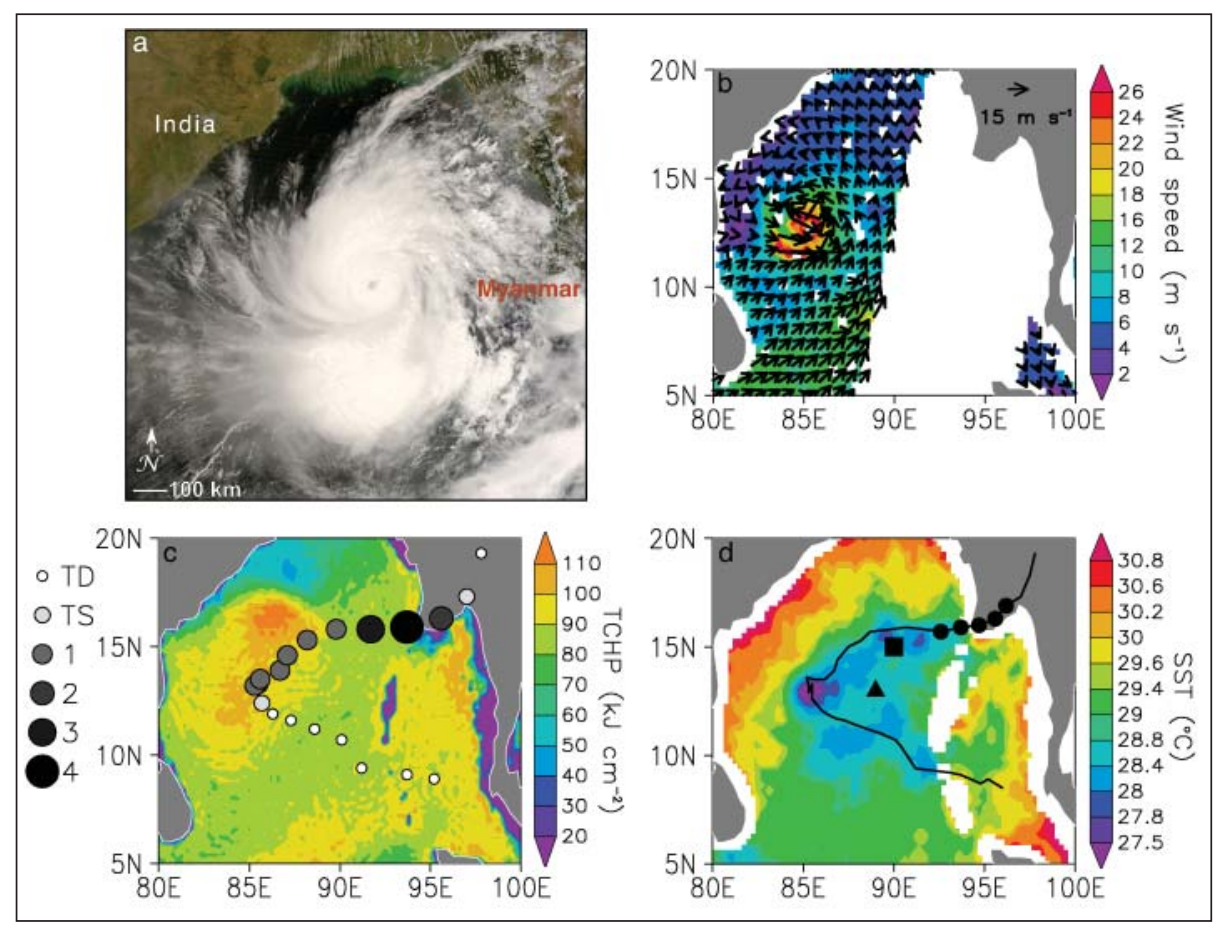

Fig. 1. (a) Moderate Resolution Imaging Spectroradiometer (MODIS) visible image, 1 May 2008 (Courtesy of NASA). (b) Quick Scatterometer (QuikSCAT) wind vectors and speeds for 28 April 2008. (c) Tropical cyclone heat potential (TCHP) climatology for April (in kilojoules per square centimeter). Anomalies for April 2008 were generally small ( \pm 10 kilojoules per square centimeter). Heat potential represents the amount of heat stored above the $26^{\circ} \mathrm{C}$ isotherm [Goni and Trinanes, 2003]. Storm intensity is shown by the dots, with TD indicating tropical depression, TS indicating tropical storm, and numbers indicating equivalent hurricane strength on the SaffirSimpson Hurricane Scale. (d) Tropical Rainfall Measuring Mission's Microwave Imager/Advanced Microwave Scanning Radiometer-EOS (TMI/AMSR-E) sea surface temperature (SST) on 2 May 2008 showing the track of Nargis; dots indicate the eye of the storm every 6 hours on 2 May. The Research Moored Array for African-Asian-Australian Monsoon Analysis and Prediction (RAMA) buoy location (square) and the Argo float location (triangle) for data shown in Figures 2 and 3 are superimposed on SST in Figure 1d. 


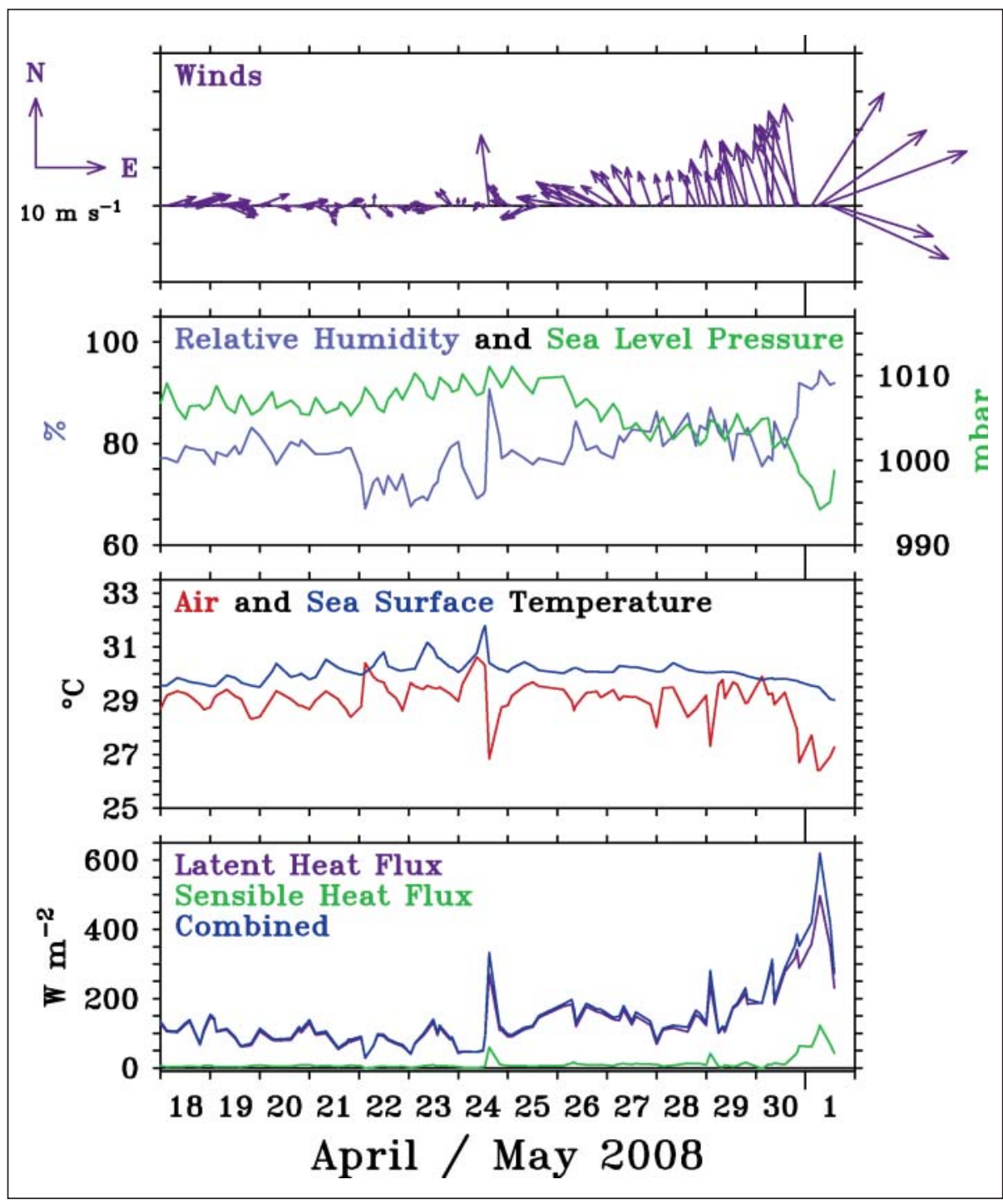

Fig. 2. Real-time surface meteorological data (approximately every 3 hours) from the $15^{\circ} \mathrm{N}, 90^{\circ} \mathrm{E}$ RAMA mooring during the approach of cyclone Nargis. Surface turbulent fluxes (latent and sensible) are estimated using a bulk algorithm. Satellite telemetry of data from the mooring stopped on 1 May as the storm passed by, though the mooring survived and all internally recorded subsurface ocean data were recovered in October 2008. Arrows in the top panel indicate wind speed and direction as per the scale on the left.

tropical storm strength (sustained winds of 63-117 kilometers per hour) on 28 April. The Indian Meteorological Department named the storm Nargis at that point and 9 hours later upgraded it to a severe (i.e., hurricane intensity) tropical cyclone. Nargis then veered to the northeast, steered by middle tropospheric winds that shifted to westerly in association with the buildup of a highpressure ridge to the south.

As Nargis approached a RAMA mooring at $15^{\circ} \mathrm{N}, 90^{\circ} \mathrm{E}$ in late April, surface pressure dropped, winds intensified, relative humidity increased, and air temperature decreased (Figure 2). Turbulent heat loss from the ocean dramatically increased to more than 600 watts per square meter for one 3 -hour period on 1 May as Nargis made its closest approach to the buoy. This heat loss helped to cool the surface and also fuel intensification of the storm (to an equivalent category
3-4 hurricane) on 1 May just before it made landfall in Myanmar [Lin et al., 2008].

\section{Ocean Response to Nargis}

High SSTs that energize tropical storms in the Bay of Bengal are maintained in part by a freshwater cap produced from river runoff and open ocean rainfall. This freshwater cap creates thin surface mixed layers atop salinity-stratified "barrier layers" that isolate the surface from colder waters of the thermocline (Figure 3). Thin mixed layers have low heat capacity so that radiant heat from the Sun can sustain elevated SSTs in the absence of strong sources of vertical turbulent mixing.

Argo float data show that the mixed layer was very thin ( $\sim 10$ meters) and SSTs were nearly $30^{\circ} \mathrm{C}$ in the central Bay of Bengal from late March to mid-April, conditions favorable for cyclone development (Figure 3). The mixing up of colder water from the thermocline at this time was inhibited by low wind speeds and relatively fresh surface salinities of less than 33. However, as the storm approached the location of the Argo float, intensifying surface winds increased turbulence generation via mechanical stirring. In addition, anticyclonically rotating winds to the right of a moving storm (as seen in Figure 2) resonantly force inertial oscillations that produce strong vertical current shears and flow instabilities, which are an additional source of turbulence [Price, 1981]. Thus, enhanced vertical mixing associated with Nargis deepened the surface mixed layer and eroded the barrier layer in the central Bay. The resulting entrainment of cold, high-salinity water from the thermocline lowered SST and increased surface salinity (Figure 3). Similarly, the diurnal cycle in SST disappeared at the RAMA mooring (Figure 2) as surface water heated by the Sun was vigorously mixed into the upper ocean.

The combined impact of Nargis on SST from enhanced ocean mixing and turbulent heat loss to the atmosphere was a $2^{\circ}-3^{\circ} \mathrm{C}$ drop in surface temperature (Figure 1d). The cooling was most pronounced to the right of the storm track especially after the storm intensified and migrated eastward, consistent with the expectation that inertial oscillations and thus enhanced vertical mixing are stronger to the right of a translating storm. Jason 1 satellite altimeter measurements indicated that significant wave heights were highest (3-4 meters) to the right of the storm where the winds were strongest (Figure 1b), which also would have contributed to vertical mixing and surface cooling. The isolated temperature minimum $\left(\mathrm{SST} \leq 27.5^{\circ} \mathrm{C}\right)$ coincided with the location where Nargis temporarily stalled and intensified on 28 April.

The hydrographic conditions that isolate the surface layer from the thermocline in the central Bay of Bengal also restrict nutrient input into the surface waters, thus leading to a persistent deep chlorophyll maximum and oligotrophic surface waters. Given the intense vertical mixing generated by Nargis, an injection of nutrients into surface waters and a subsequent phytoplankton bloom would be expected within the cool SST wake, a biological response observed in past hurricanes. Ocean color retrievals following Nargis's passage were sparse due to interference from extensive cloud cover. However, the available Sea-viewing Wide Field-of-view Sensor (SeaWiFS) data suggest up to a threefold increase in chlorophyll concentrations (to $0.3-0.5$ milligrams chlorophyll per cubic meter) over normal conditions.

\section{Science in Service to Society}

Although IndOOS is only partially complete, with some components such as RAMA a few years from full implementation, it is already providing unique data for studies of tropical cyclones like Nargis, ocean-atmosphere interactions associated with the 30- to 60-day-period Madden-Julian 




Fig. 3. Argo float temperature (middle) and salinity (bottom) profile data with 3-day average QuikSCAT winds (top) for mid-March to 1 June 2008. Circles indicate the dates of Argo profiles. The solid curve plotted over temperature and salinity is a measure of mixed-layer depth based on a density increase of 0.15 kilograms per cubic meter relative to 5 meters. The dashed curve is a measure of mixed-layer depth based on a temperature decrease of $0.5^{\circ} \mathrm{C}$ relative to 5 meters. The two measures of mixed-layer depth are identical in the absence of salinity stratification; divergence of the two lines indicates the presence of a salinity-stratified barrier layer separating the surface mixed layer from the top of the thermocline.

Oscillation [Vialard et al., 2008], year-toyear changes linked to the Indian Ocean dipole [Horii et al., 2008], and Indian Ocean circulation [Nagura and McPhaden, 2008]. Science and technology have a role to play in mitigating risks related to weather and climate hazards that plague the Indian Ocean region. Ultimately, one hopes that the development of IndOOS as part of a regional early warning system will inform wise government policies and disaster preparedness plans to ensure that tragedies like Nargis do not repeat.

\section{Acknowledgments}

The authors thank Gustavo Goni for providing tropical cyclone heat potential data.
This is Pacific Marine Environmental Laboratory contribution 3274 and National Institute of Oceanography contribution 4481.

\section{References}

Goni, G. J., and J. A. Trinanes (2003), Ocean thermal structure monitoring could aid in the intensity forecast of tropical cyclones, Eos Trans. AGU, 84(51), 573, 577-578.

Horii, T., H. Hase, I. Ueki, and Y. Masumoto (2008), Oceanic precondition and evolution of the 2006 Indian Ocean dipole, Geophys. Res. Lett., 35, L03607, doi:10.1029/2007GL032464.

Lin, I.-I., C.-H. Chen, I.-F. Pun, W. T. Liu, and C.-C. Wu (2009), Warm ocean anomaly, air sea fluxes, and the rapid intensification of tropical cyclone Nargis (2008), Geophys. Res. Lett., 36, L03817, doi:10.1029/2008GL035815.

McPhaden, M. J., G. Meyers, K. Ando, Y. Masumoto, V. S. N. Murty, M. Ravichandran, F. Syamsudin, J. Vialard, L. Yu, and W. Yu (2009), RAMA: The Research Moored Array for African-AsianAustralian Monsoon Analysis and Prediction, Bull. Am. Meteorol. Soc., in press.

Meyers, G., and R. Boscolo (2006), The Indian Ocean Observing System (IndOOS), CLIVAR Exch., 11(4), 2-3.

Nagura, M., and M. J. McPhaden (2008), The dynamics of zonal current variations in the central equatorial Indian Ocean, Geophys. Res. Lett., 35, L23603, doi:10.1029/2008GL035961.

Price, J. F. (1981), Upper ocean response to a hurricane, J. Phys. Oceanogr., 11, 153-175.

Vialard, J., G. R. Foltz, M. J. McPhaden, J. P. Duvel, and C. de Boyer Montégut (2008), Strong Indian Ocean sea surface temperature signals associated with the Madden-Julian Oscillation in late 2007 and early 2008, Geophys. Res. Lett., 35, L19608, doi:10.1029/2008GL035238.

Webster, P. J. (2008), Myanmar's deadly "daffodil," Nat. Geosci., 1, 488-490.

\section{Author Information}

Michael J. McPhaden, Pacific Marine Environmental Laboratory, National Oceanic and Atmospheric Administration (NOAA), Seattle,Wash.; E-mail: michael.j.mcphaden@noaa.gov; Gregory R. Foltz, Joint Institute for the Study of the Atmosphere and Ocean, University of Washington, Seattle; Tony Lee, Jet Propulsion Laboratory, Pasadena, Calif.; V.S. N. Murty, Regional Center, National Institute of Oceanography,Visakhapatnam, India; M. Ravichandran, Indian National Center for Ocean Information Services, Hyderabad, India; Gabriel A. Vecchi, Geophysical Fluid Dynamics Laboratory, NOAA, Princeton, N. J.; Jerome Vialard, Institut de Recherche pour le Développement/Laboratoire d'Océanographie et du Climat: Expérimentation et Approches Numériques, Paris, France; Jerry D. Wiggert, Department of Marine Science, University of Southern Mississippi, Stennis Space Center; and Lisan Yu,Woods Hole Oceanographic Institution, Woods Hole, Mass. 


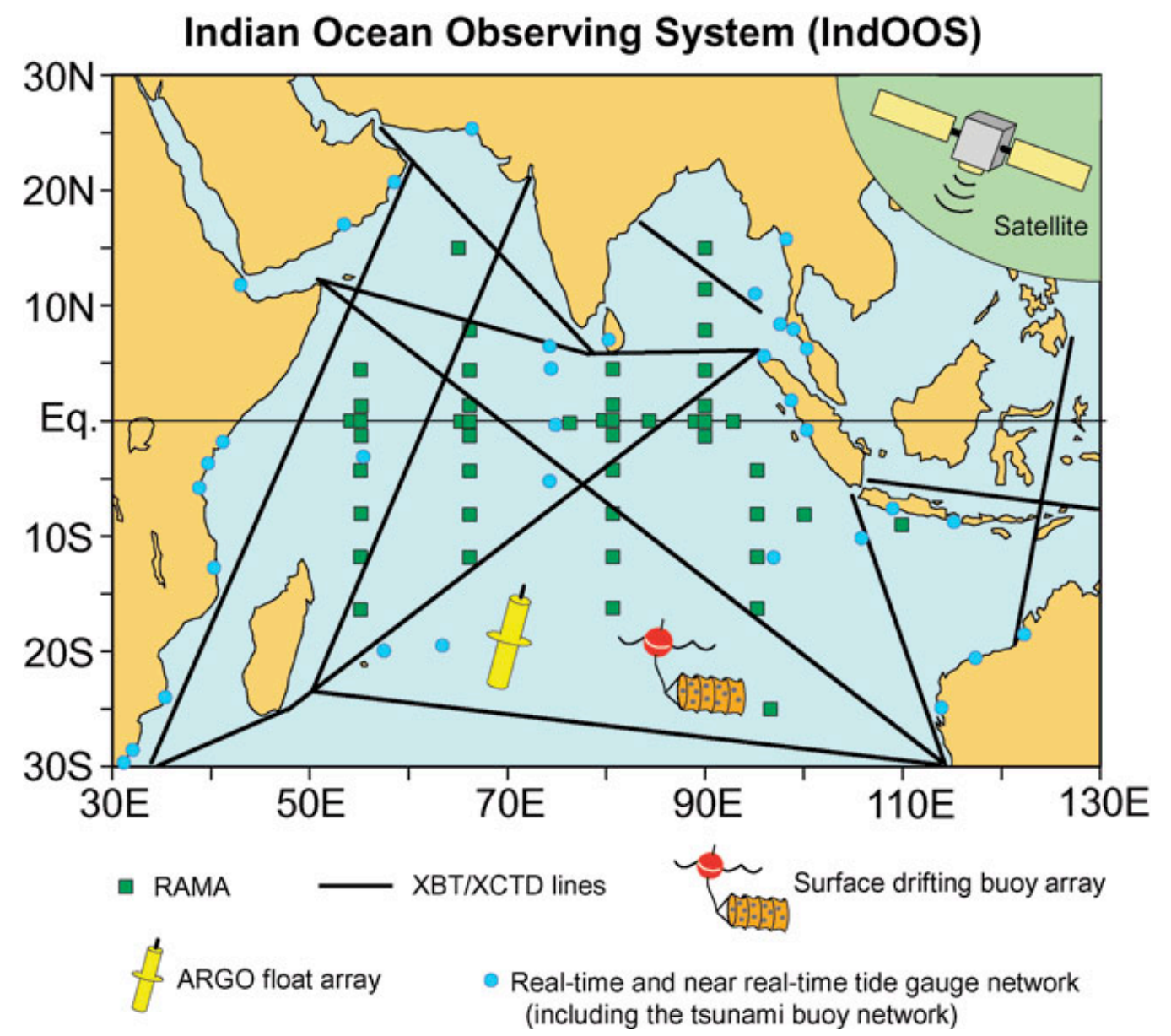

Fig. S1. Schematic of the Indian Ocean Observing System (IndOOS). Green squares indicate the locations of RAMA moorings, with 22 of 46 planned sites occupied as of 30 November 2008. Argo floats and surface drifters are indicated by a single symbol, although many floats and drifters are spread throughout the basin (117 drifters and 414 Argo floats as of 30 November 2008). Expendable bathythermograph (XBT) and expendable conductivity/temperature/depth (XCTD) sections sampled by ships of opportunity are shown as black lines. Most of these lines are sampled 12-18 times per year at along-track intervals of approximately $1^{\circ}$ (though the Australia-Sumatra line and the Australia-Mauritius-South Africa line are sampled more frequently to measure details of ocean circulation). Tide gauges are indicated by blue dots. Nationally sponsored regional observing systems and process studies are also embedded in IndOOS. The satellite in the upper right symbolizes the constellation of Earth-observing satellites for SST, surface winds, sea level, and other important oceanic and atmospheric parameters.

$A G U$ is a worldwide scientific community that advances, through unselfish cooperation in research, the understanding of Earth and space for the benefit of humanity. 